\title{
ASSESSMENT OF SURFACE CONDITION OF CEMENTITIOUS MATERIALS SUBJECTED TO LASER RADIATION
}

\author{
A.J. KLEMM ${ }^{1}$, P. SANJEEVAN ${ }^{1} \&$ K. ROZNIAKOWSKI ${ }^{2}$ \\ ${ }^{1}$ School of Engineering and Built Environment, Glasgow Caledonian University, UK. \\ ${ }^{2}$ Institute of Physics, Technical University of Lodz, Poland.
}

\begin{abstract}
The paper is focused on the assessment of laser-treated cementitious surfaces. It forms part of the larger study on laser cleaning process and its effect on modification of geometrical microstructure of cementitious composites. The great variation in absorptivity of highly developed surfaces of cementitious materials results in substantial differences in their responses to laser irradiation. Even though lasers can be successfully used to remove dirt from mortar surfaces, there are always some residual surface alterations associated with the removal of mortar, formation of cracks and glazing (melted mortar). Comprehensive understanding of surface processes resulting from laser interaction with substrate is essential in further industrial commercialisation of the technology. In order to address the problem a wide range of laser-treated samples with different internal microstructures, surface roughness and moisture content were studied. The characteristic features of all laser-cleaned areas included removal of mortar, formation of cracks and glassy patches. Systematic analysis of surface modifications resulting from laser cleaning confirmed a strong relationship between initial roughness of surfaces and their end conditions. An increase in initial surface roughness leads to more pronounced alterations in roughness and reduced tendency towards crack formation.
\end{abstract}

Keywords: Cementitious surfaces, crack propagation, laser cleaning, porosity, surface roughness.

\section{INTRODUCTION}

Cleaning of materials' surfaces by lasers has been first introduced in early 1970s and since then has been progressively developed. Over the years, different types of lasers (Ruby laser, $\mathrm{CO}_{2}$ lasers, $\mathrm{Nd}$ :YAG lasers and a number of excimer laser systems) have been used to clean surfaces, such as stained glass, steel, photographs, tiles, paper and parchment, concrete, leather and limestone [1-7]. Application of laser cleaning to cementitious surfaces is far more complex. The great variation in absorptivity of highly developed surfaces of cementitious materials results in substantial differences in their responses to laser irradiation. Although lasers can be successfully used to remove dirt from mortar surfaces, their application results in an inevitable residual surface alterations, associated with the removal of mortar, formation of cracks and glazing (melted mortar). Despite the fact that these effects are generally microscopic and only visible at high magnification, their importance should not be underestimated, especially on national heritage buildings as they may expose surfaces to further accelerated environmental deterioration.

The relationship between laser cleaning processes and substrate parameters is a two-way relationship. While the influence of microstructural features of surfaces on laser cleaning process has been previously researched [3,8-10], the effect of laser radiation on characteristics of modified cementitious surfaces has been slightly overlooked. Laser cleaning is often described as a self-limiting process. The mechanism of this process is based on the difference between the monochromatic reflection (absorption) of photons by the contaminator and the background [4]. Improper selection of laser parameters may result in a severe damage of 
surface due to a high surface temperature rise. In the heat-affected zone, water/air in the pores absorbs the heat and expands leading to a pressure build up and cracking [8]. Cracks may also develop in interfacial zones between aggregate and hardened cement paste due to their different thermal expansion coefficients.

\section{EXPERIMENTAL DETAILS}

Analysed samples differ in their microstructure (low porosity - LP and high porosity - HP), surface roughness (A, B and C) and moisture content (WET - fully saturated with water and DRY - air dry). The mortar specimens had the following composition: cement to sand ratio $1: 1$ and water/cement $(\mathrm{w} / \mathrm{c})$ ratio 0.4 . Different porosities were obtained by applying air-entraining admixture (AEA). Table 1 presents mechanical properties, surface roughness and moisture content of mortars [11].

Surface roughness was measured by a stylus device and represented by average surface roughness (Ra). A total of 50 points per sample were measured to find the $95 \%$ confidential interval of the surface roughness.

The cleaning of spray paint from mortar surfaces was done with application of Nd:YAG laser with the following characteristics: wavelength: $1.06 \mu \mathrm{m}$, energy: $500 \mathrm{~mJ}$, pulse duration: $10 \mathrm{~ns}$ and pulse repetition rate: $1 \mathrm{~Hz}$. Each sample has been subjected to laser radiation of the same laser fluence, $\mathrm{F}=3.06 \mathrm{~J} / \mathrm{cm}^{2}$. Increasing number of pulses has been applied to 11 areas as shown in Fig. 1.

Table 1: Physical and mechanical properties of all tested mortar samples [11].

\begin{tabular}{|c|c|c|c|c|c|c|c|c|}
\hline \multirow[b]{2}{*}{ Mix } & \multirow{2}{*}{$\begin{array}{c}\text { AEA } \\
(\%)\end{array}$} & \multirow{2}{*}{$\begin{array}{l}\text { Surface } \\
\text { roughness } \\
95 \% \text { conf. } \\
\text { interval }\end{array}$} & \multirow{2}{*}{$\begin{array}{c}\text { Compressive } \\
\text { strength } \\
\left(\mathrm{N} / \mathrm{mm}^{2}\right)\end{array}$} & \multirow{2}{*}{$\begin{array}{l}\text { Flexural } \\
\text { strength } \\
\left(\mathrm{N} / \mathrm{mm}^{2}\right)\end{array}$} & \multirow{2}{*}{$\begin{array}{l}\text { Bulk } \\
\text { density } \\
(\mathrm{g} / \mathrm{ml})\end{array}$} & \multirow{2}{*}{$\begin{array}{c}\text { Porosity }(\varepsilon \mathrm{Hg}) \\
\%\end{array}$} & \multicolumn{2}{|c|}{$\begin{array}{l}\text { Moisture } \\
\text { content }\end{array}$} \\
\hline & & & & & & & DRY & WET \\
\hline LP-A & 0 & $2.28-2.49$ & 79.4 & 8.3 & 2.16 & 11.9 & 2.3 & 8.2 \\
\hline LP-B & 0 & $7.70-8.49$ & 79.4 & 8.3 & 2.16 & 11.9 & 2.3 & 8.2 \\
\hline LP-C & 0 & $15.58-17.89$ & 79.4 & 8.3 & 2.16 & 11.9 & 2.3 & 8.2 \\
\hline HP-A & 1.3 & $2.28-2.49$ & 57.5 & 7.4 & 1.8 & 26.4 & 3.2 & 10.7 \\
\hline HP-B & 1.3 & $7.70-8.49$ & 57.5 & 7.4 & 1.8 & 26.4 & 3.2 & 10.7 \\
\hline HP-C & 1.3 & $15.58-17.89$ & 57.5 & 7.4 & 1.8 & 26.4 & 3.2 & 10.7 \\
\hline
\end{tabular}

Figure 1: Mortar sample after cleaning process. 


\section{RESULTS AND DISCUSSION}

\subsection{Crack propagation}

Comprehensive SEM analysis of surfaces revealed a high number of microcracks and glazing as shown in Fig. 2. Cracks were quantified by their density, defined by the length of the crack by the area. Backscattered electron (BSE) image analyses have been used to calculate crack densities. The actual lengths of cracks were approximated by straight lines. The white lines on Fig. 2 consisting of short straight lines represent actual cracks.

Any interaction of the laser with mortar leads to the production of a significant amount of heat. The heat produced dissipates through the formations of cracks, glazing, removal of paint or mortar and other losses.

Mortar surfaces can develop cracks in two different ways. Cracks may form, when thermal stresses on the cementitious material due to application of laser exceed its tensile strength or when the tensile stresses due to expansion of water or air inside the pores exceed the tensile strength of material (Fig. 3) [12].

Since thermal conductivity of a wet mortar sample is higher than a dry one, the temperature difference between two points is greater for dry samples [13]. Thus, the development of thermal stress, resulting from laser cleaning of dry samples, is more pronounced. The wetness of the samples impedes the crack formation in the first mechanism. On the other hand, since development of pressure in pores depends on the amount of water inside them, wetness

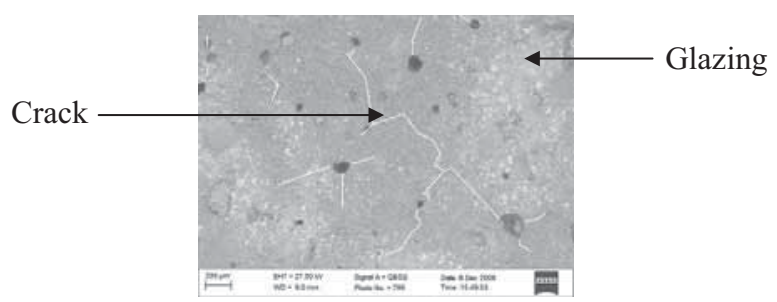

Figure 2: BSE image of HP-C(WET) after the application of 26 laser pulses (150×).

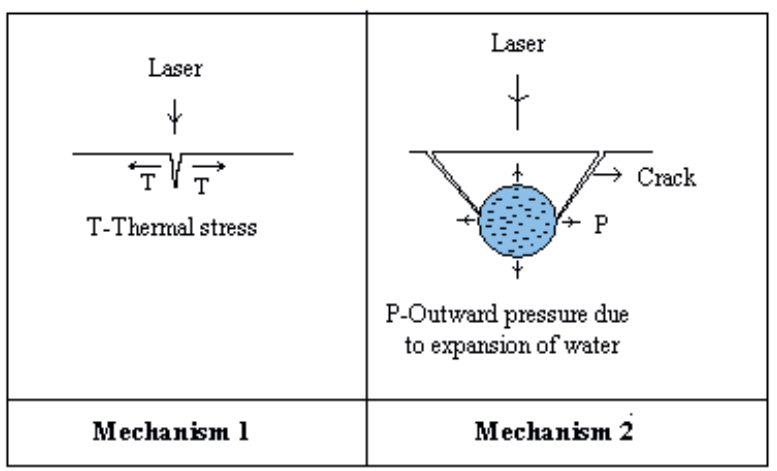

Figure 3: Mechanisms of formation of cracks due to laser cleaning. 
of mortar facilitates crack formation in the second mechanism. Figures 4 to 6 show the relationship between number of pulses applied to the surface and crack density in the laser affected area.

As the number of laser pulses increased, the crack density also increased up to a certain level, followed by their disappearance, which was caused by the removal of mortar. Further application of pulses has lead to the formation of new cracks. Figure 7 shows the disappearance of cracks, due to removal of mortar.
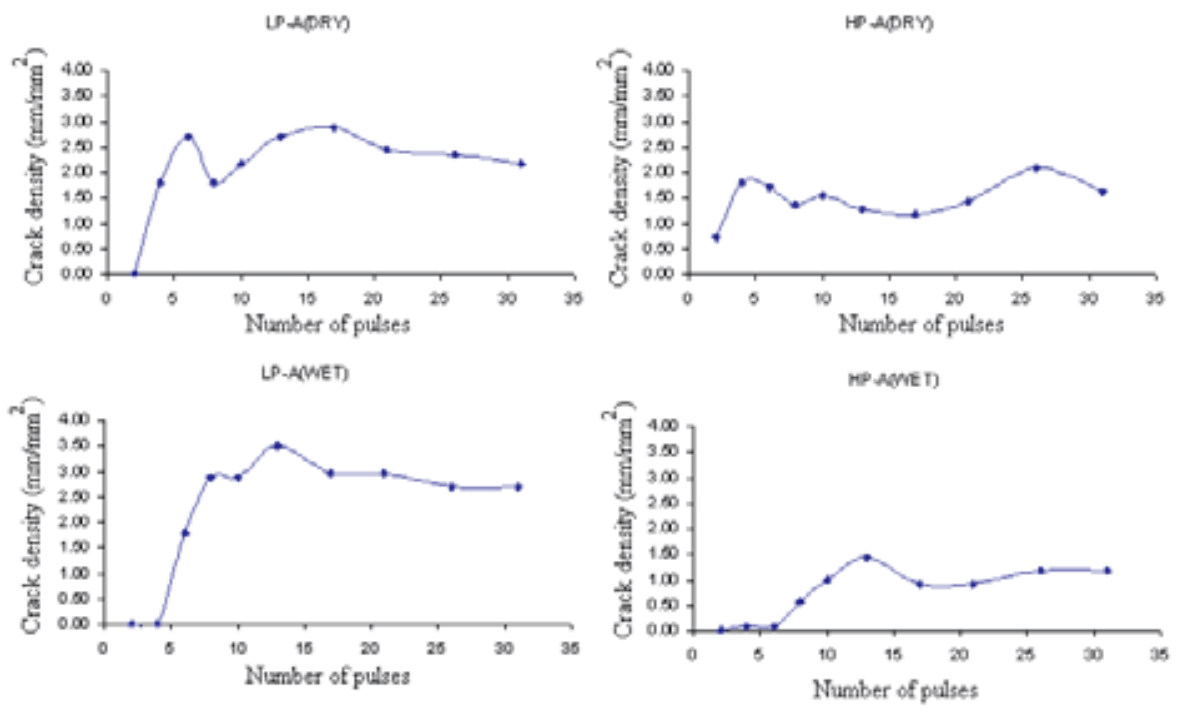

Figure 4: Crack density in the function of number of pulses; $\mathrm{Ra}=2.28-2.49 \mu \mathrm{m}$.
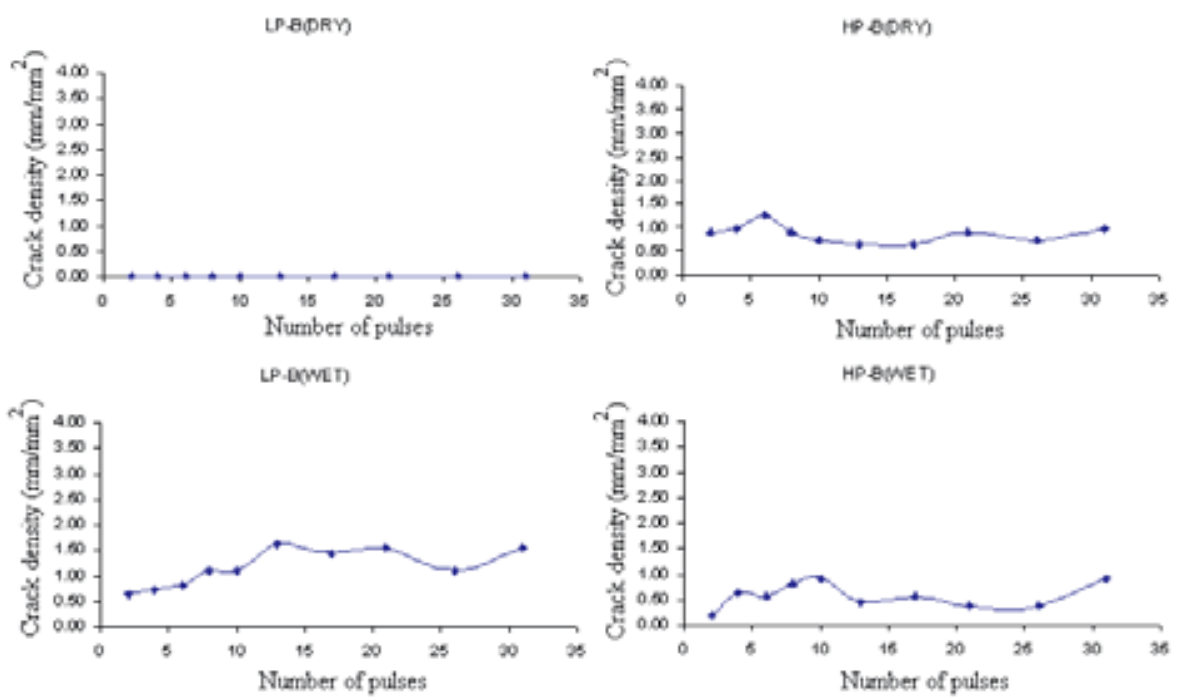

Figure 5: Crack density in the function of number of pulses; $\mathrm{Ra}=7.70-8.49 \mu \mathrm{m}$. 

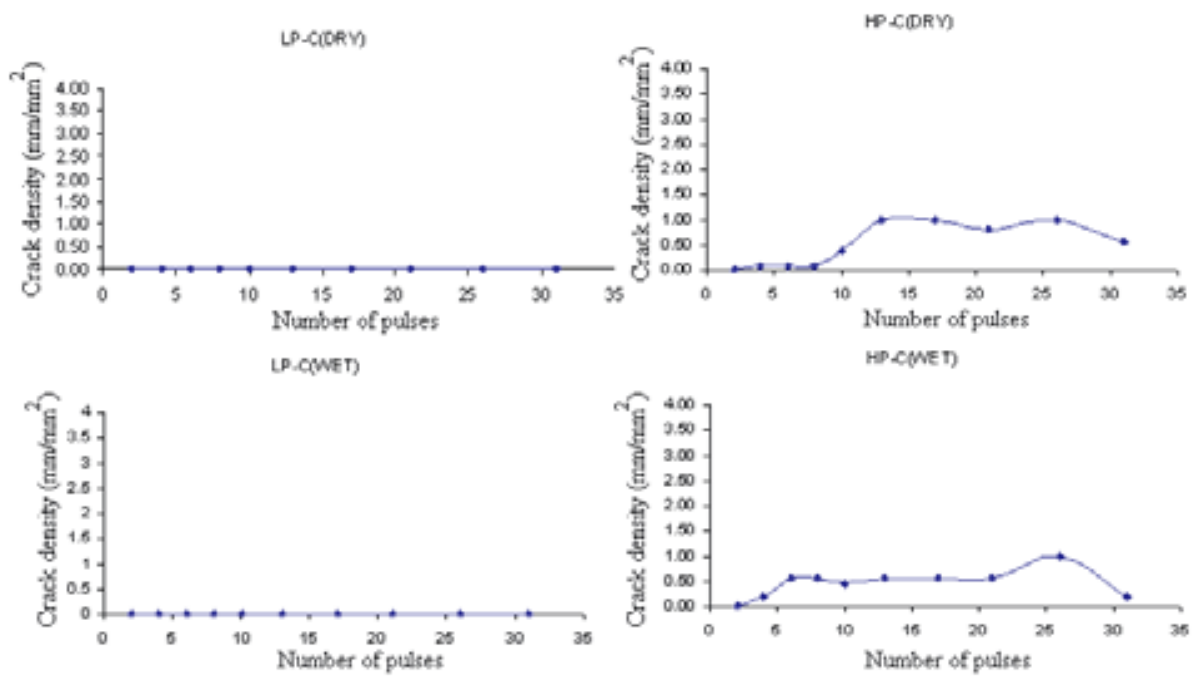

Figure 6: Crack density in the function of number of pulses; $\mathrm{Ra}=15.58-17.89 \mu \mathrm{m}$.

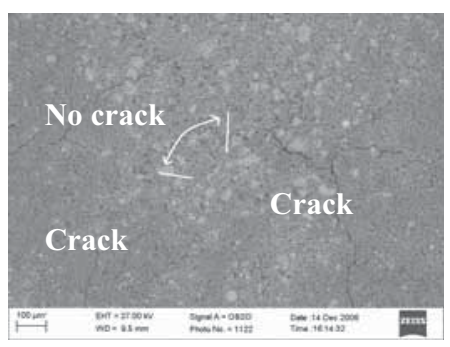

Figure 7: BSE image of LP-A(DRY) (150×) after the application of 31 pulses.

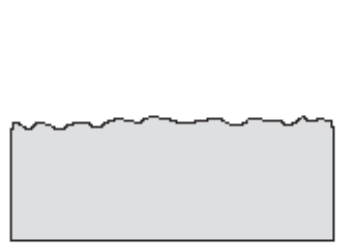

(a)

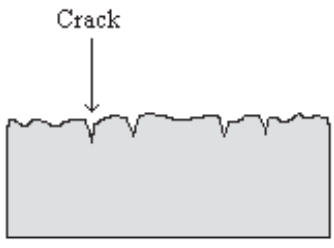

(b)

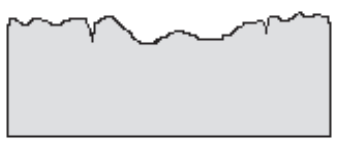

(c)

Figure 8: Morphology of mortar surface: (a) before the laser application; (b) after the application of $\mathrm{N}$ number of pulses; (c) after the application of $(\mathrm{N}+\mathrm{n})$ number of pulses. Cracks start to disappear as a result of mortar removal.

Figure 8 shows the schematic representation of above process.

Regardless of the surface roughness and moisture content of the mortar, cracks always form in more porous samples, mainly due to the presence of pit holes. On the other hand, no crack formation was observed when the laser was applied to low porosity samples (LP-C(WET), LP-C(DRY) and LP-B(DRY)). Pit holes have better absorption characteristics 
than the other parts of mortar. A high temperature gradient due to the geometrical shape of holes leads to a higher concentration of cracks around them. An example is shown in Fig. 9 below.

Figure 10 shows the effect of moisture content and porosity of mortar on the crack formation on surfaces with low surface roughness, between 2.28 and $2.49 \mu \mathrm{m}$ (A).

The formation of cracks due to laser cleaning was found to be more pronounced in denser samples. For example, the crack density of LP-A(WET) after the application of 31 laser pulses was $2.7 \mathrm{~mm} / \mathrm{mm}^{2}$ and the crack density of HP-A(WET) after the application of 31 pulses was only $1.17 \mathrm{~mm} / \mathrm{mm}^{2}$. Moreover, presence of water in mortar facilitated the crack formation in low porosity samples. Highly porous samples experienced the opposite. This leads to the conclusion that low porosity is responsible for the crack formation, mainly due to build up of internal pressures caused by expansion of water/air inside the pores. However, in more porous samples, crack formation is mainly caused by thermal stress on the mortar surface. Figure 11 shows the spalling caused by laser cleaning of a less porous wet mortar sample. Since spalling of mortar results from built up of internal pressure due to expansion of water inside the pores, the above surmise is correct.

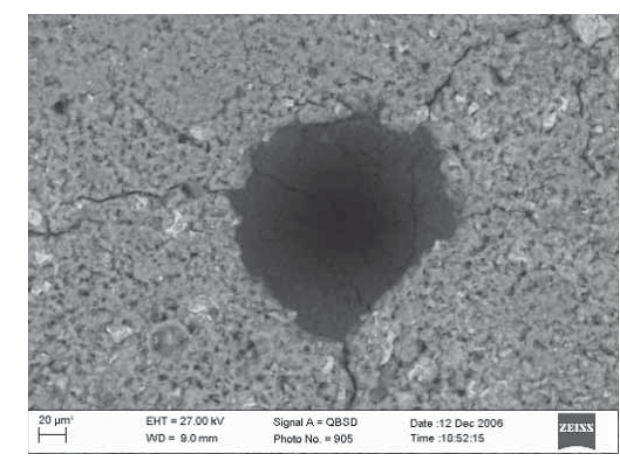

Figure 9: BSE image of HP-A(WET) (1000x) after the application of 31 laser pulses.

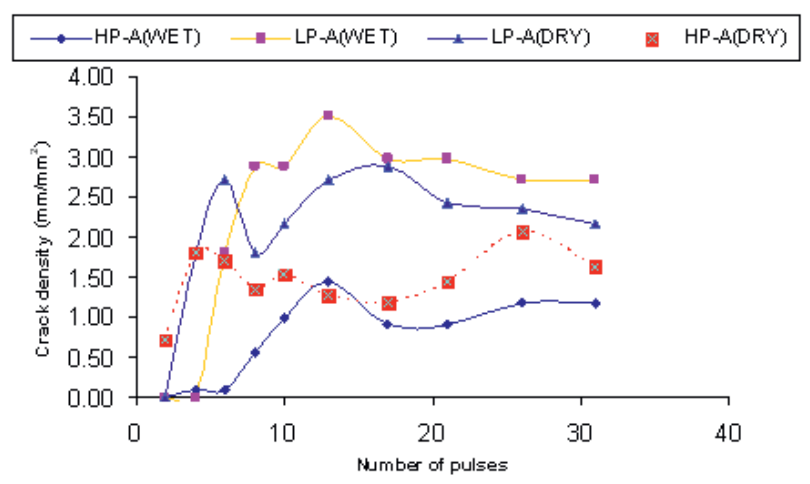

Figure 10: Effect of surface moisture content and porosity of mortar on the crack formation; $\mathrm{Ra}=2.28-2.49 \mu \mathrm{m}$. 


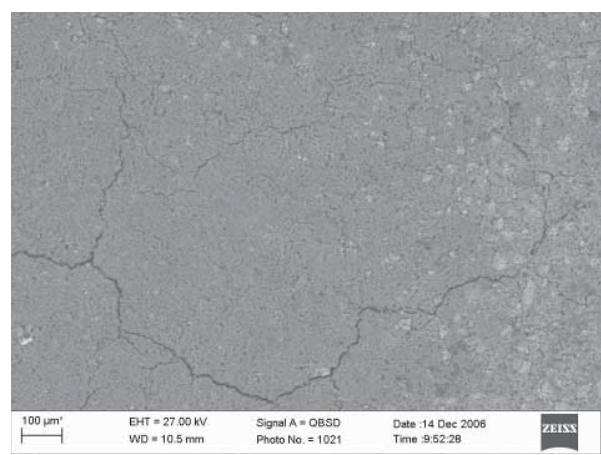

Figure 11: BSE image of LP-A(WET) (150×) after the application of 31 laser pulses. Spalling of mortar was observed.

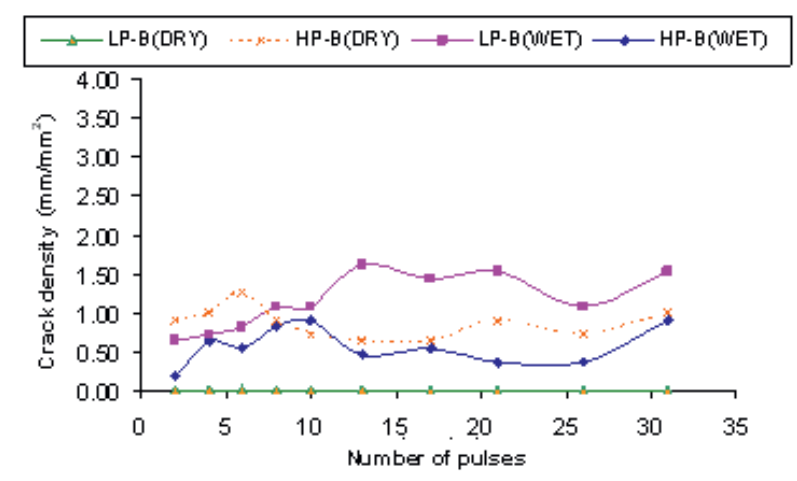

Figure 12: Effect of surface moisture content and porosity of mortar on the crack formation; $\mathrm{Ra}=7.70-8.49 \mu \mathrm{m}$.

Figure 12 shows the effect of moisture content and porosity of the mortar with the surface roughness of $7.70-8.49 \mu \mathrm{m}(\mathrm{B})$, on the crack formation. Similar to the previous case (A), the wetness of the sample facilitates the crack formation in low porosity mortars and impedes formation in high porosity ones. The crack formation in HP-B(DRY) is more pronounced than in LP-B(DRY) mainly because of the presence of pit holes in HP-B(DRY).

Figure 13 shows the effect of moisture content and porosity of the mortar sample on the crack formation due to laser cleaning, when the initial surface roughness was 15.58-17.89 $\mu \mathrm{m}$. No crack formations were observed in denser/rougher surfaces.

The effect of surface roughness of mortar on the crack formation due to laser cleaning is shown in Fig. 14. Crack density on smooth surfaces was higher than on rough ones, probably due to the higher energy dissipation through mortar removal rather than crack formation in the rougher surface. Since crack density depends on the amount of energy used to produce cracks, the number of cracks developed on the smooth surface was higher than the rough one. 


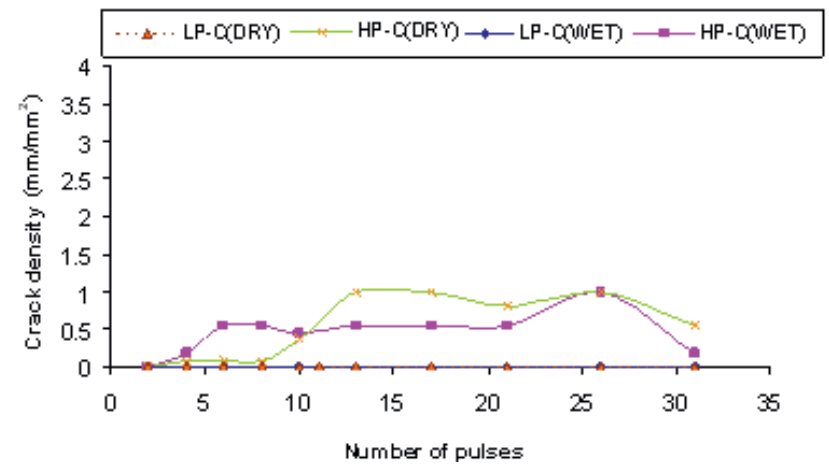

Figure 13: Effect of surface moisture content and porosity of mortar on the crack formation; $\mathrm{Ra}=15.58-17.89 \mu \mathrm{m}$.
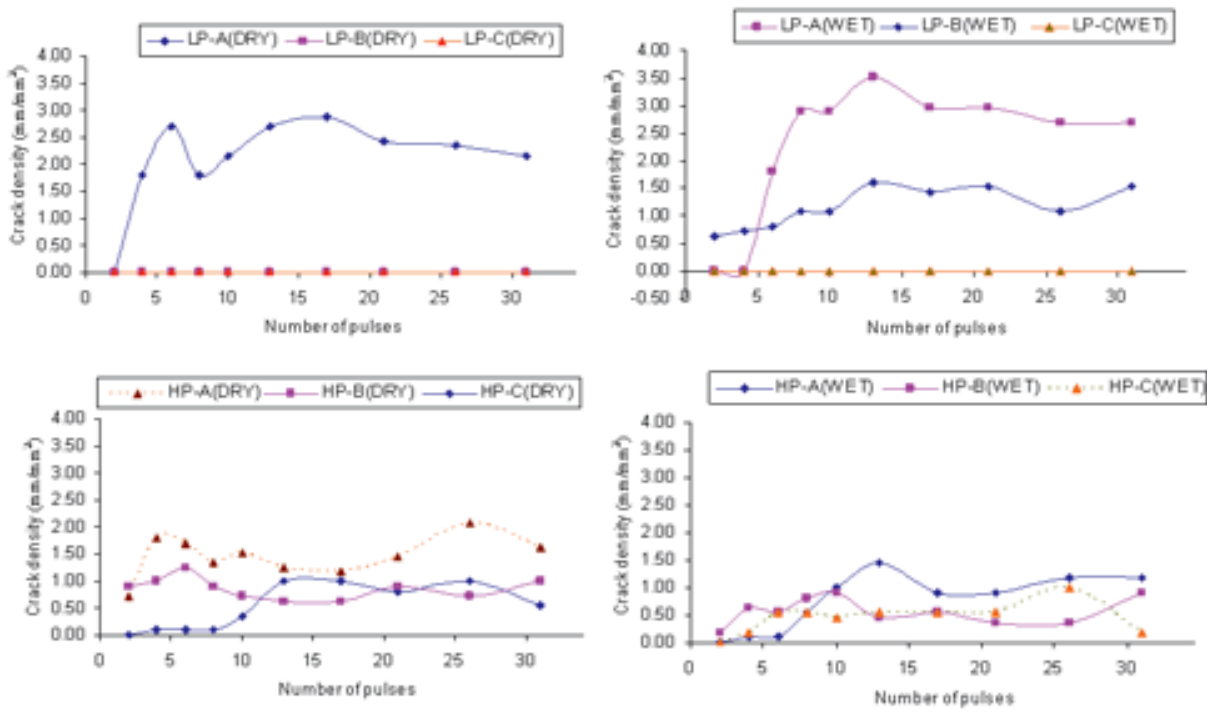

Figure 14: Effect of surface roughness of mortar on the crack formation.

The maximum width of the cracks on the surface varied from 0 to $7 \mu \mathrm{m}$ with respect to different sample conditions (Table 2). The width of the cracks formed by thermal expansion (mechanism 1) is smaller than for those formed by internal pressures (mechanism 2). For example, the width of a crack was higher in sample LP-A(WET) than HP-A(WET).

\subsection{Surface roughness}

The next stage of assessment focused on the effect of laser on surface roughness of mortars. Variations in surface roughness as function of a number of pulses applied are presented in Figs 15 to 17. Figure 15 relates to the samples of initial roughness (before laser cleaning) of 2.28-2.49 $\mu \mathrm{m}$ (sample A). The relationship can be divided into two zones of increasing roughness. The higher rate of increase in surface roughness in Zone 1 was probably caused 
Table 2: Maximum crack width with respect to different sample characteristics.

\begin{tabular}{lcl}
\hline Sample code & Maximum crack width $(\mu \mathrm{m})$ & Crack formation mechanism \\
\hline HP-A (WET) & 3.5 & Thermal expansion \\
HP-A (DRY) & 5 & Thermal expansion \\
LP-A (WET) & 7 & Internal pressure \\
LP-A (DRY) & 4 & Internal pressure \\
HP-B (WET) & 3.5 & Thermal expansion \\
HP-B (DRY) & 3.5 & Thermal expansion \\
LP-B (WET) & 4.5 & Internal pressure \\
LP-B (DRY) & 0 & N/A \\
HP-C (WET) & 3.5 & Thermal expansion \\
HP-C (DRY) & 3.5 & Thermal expansion \\
LP-C (WET) & 0 & N/A \\
LP-C (DRY) & 0 & N/A \\
\hline
\end{tabular}
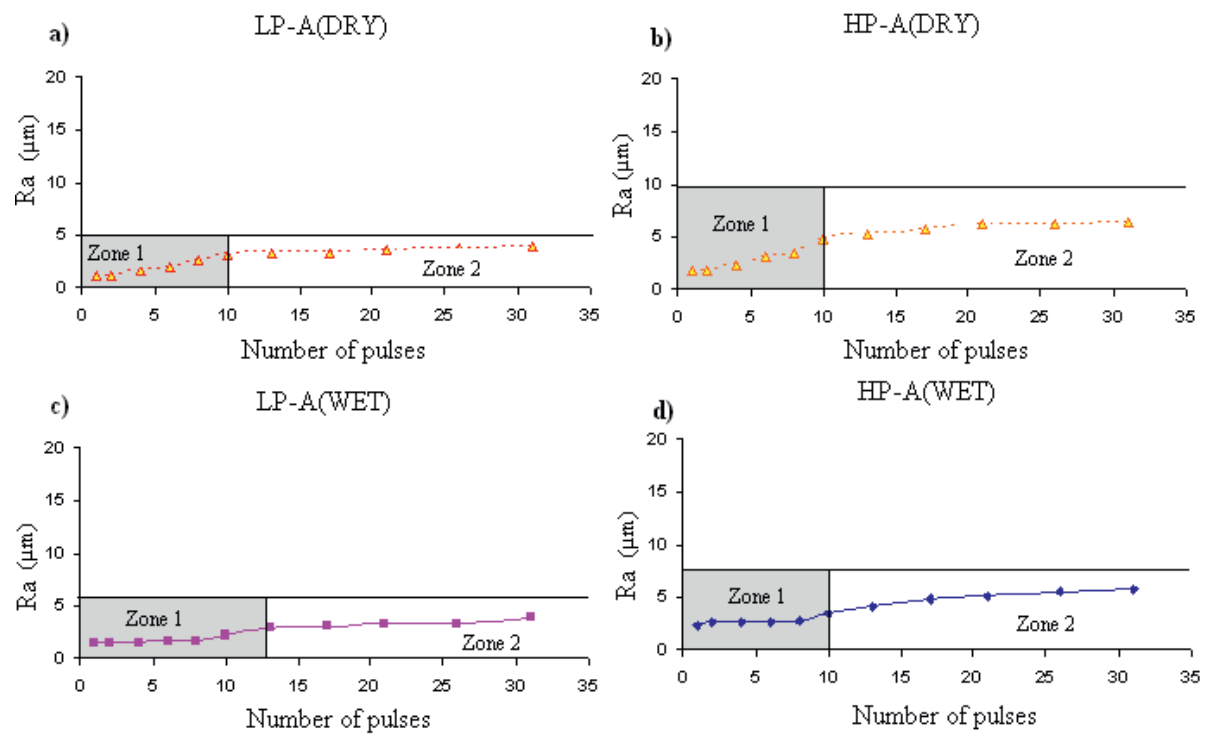

Figure 15: Variation of surface roughness of the mortar surface due to the application of laser pulses; sample A.

by the removal of paint, while the lower increment in Zone 2 could be attributed to the removal of mortar.

Second set of graphs in Fig. 16, dealing with mortars of initial roughness $7.70-8.49 \mu \mathrm{m}$ (sample B), shows similar relationship as in the above case.

Sample C (15.58-17.89 $\mu \mathrm{m})$ behaved differently to the previous ones (Fig. 17). Here, the relationship can be divided into three and four zones, depending on the samples' porosity: Zone $\mathbf{1}$ - increment in surface roughness at decreasing rate; Zone $\mathbf{2}$ - increment 

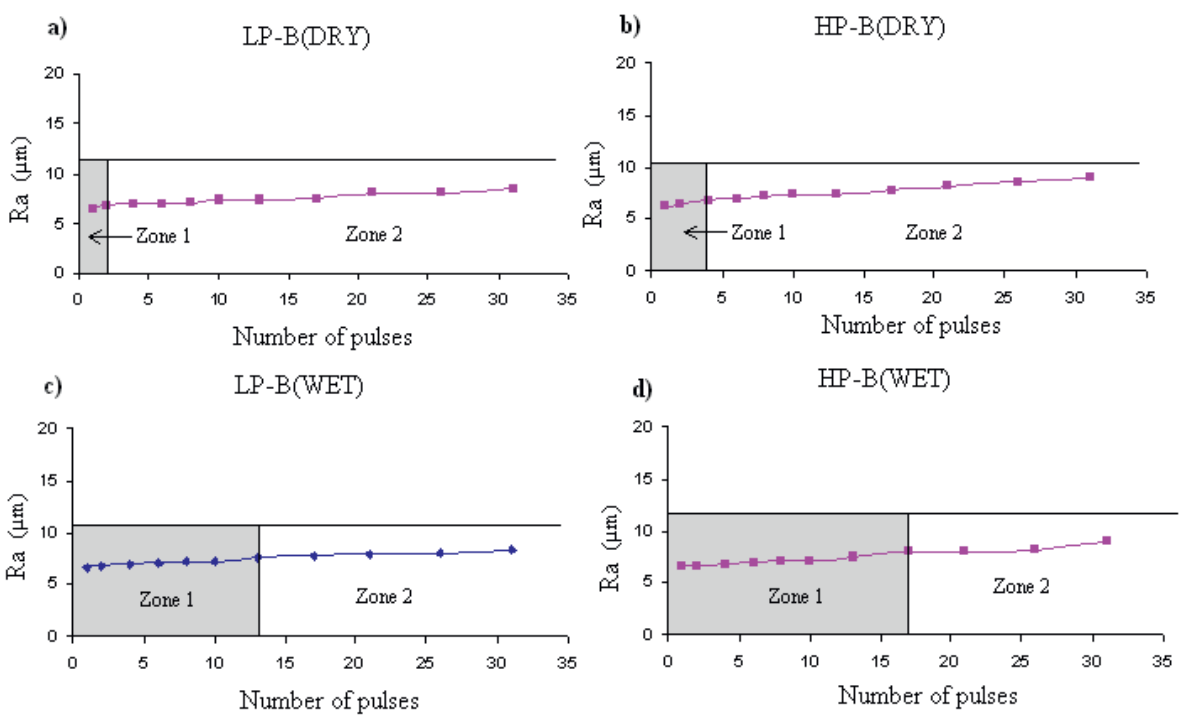

Figure 16: Variation of surface roughness of the mortar surface due to the application of laser pulses; sample B.

a)

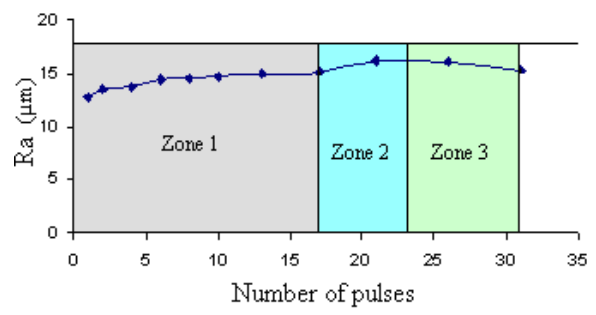

c)

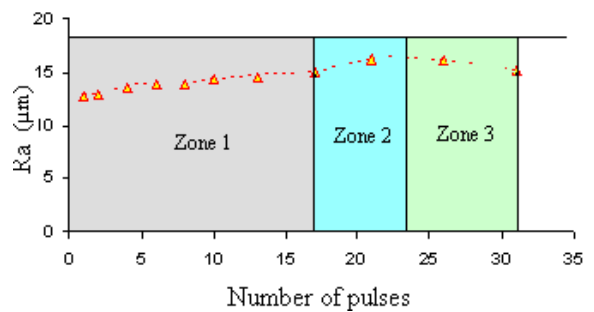

b)

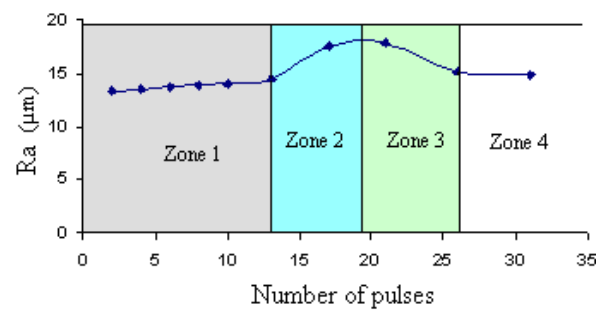

HP-C(WET)

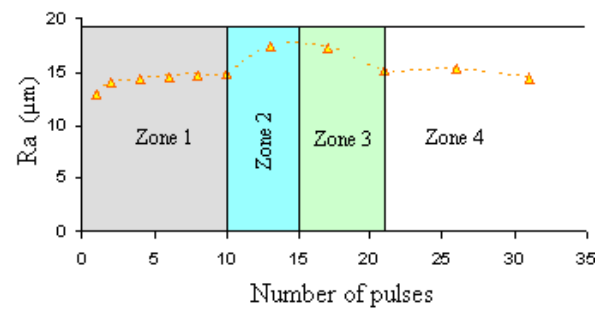

Figure 17: Variation of surface roughness of the mortar surface due to the application of laser pulses; sample C.

in surface roughness at higher rate than in Zone 1; Zone 3 - drop in surface roughness; Zone 4 - drop in surface roughness at smaller rate than in Zone 3.

The four zones were observed only in highly porous samples. In low porosity samples, three zones could be distinguished. The observed drop in the surface roughness indicates high possibility of laser damage on rough surfaces. 
The effect of laser cleaning on surface roughness is influenced by the other substrate parameters. The effects of porosity and moisture content on the variation of surface roughness with respect to number of pulses applied have been summarised for samples of different initial surface characteristics and presented in Figs 18 to 20 below. Data presented in Fig. 18 are for samples with initial surface roughness between 2.28 and $2.49 \mu \mathrm{m}(\mathrm{A})$. The effect of moisture content and porosity was noticeable after the application of four to six laser pulses. The increment of the surface roughness due to laser cleaning was higher in samples of higher porosity. Due to the lower strength of highly porous samples, the removal of mortar resulting from laser cleaning was more pronounced. Moreover, the absence of water in mortar appeared to promote the increment of surface roughness.

Figure 19 shows the effects of porosity and moisture content on the variation of surface roughness for samples with the initial surface roughness between 7.70 and $8.49 \mu \mathrm{m}(\mathrm{B})$. The effect of moisture content and porosity was prominent after the application of 17 to 21 pulses and similar to the above case $(\mathrm{Ra}=2.28-2.49 \mu \mathrm{m})$.

The effects of moisture content and porosity on the variation of surface roughness in mortar samples with the initial surface roughness between 15.58 and $17.89 \mu \mathrm{m}(\mathrm{C})$ were not clearly defined (Fig. 20).

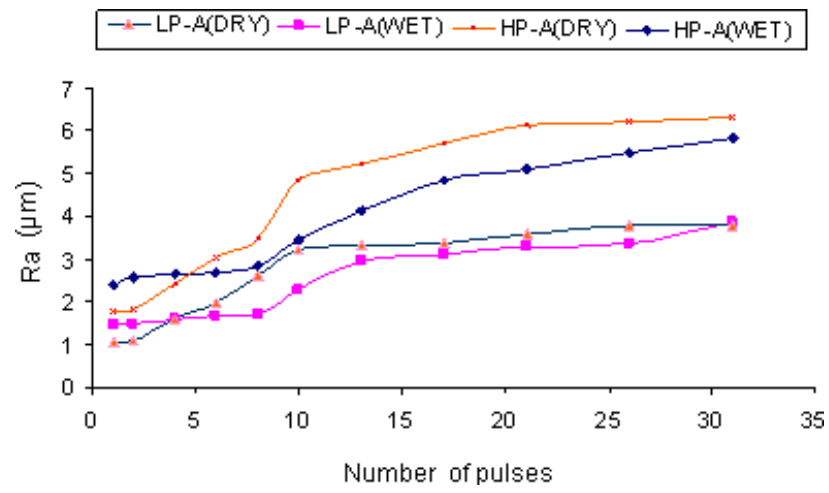

Figure 18: Porosity and moisture content on the surface roughness as a function of number of pulsed applied; $\mathrm{Ra}=2.28-2.49 \mu \mathrm{m} ; \mathrm{F}=3.06 \mathrm{~J} / \mathrm{cm}^{2}$.

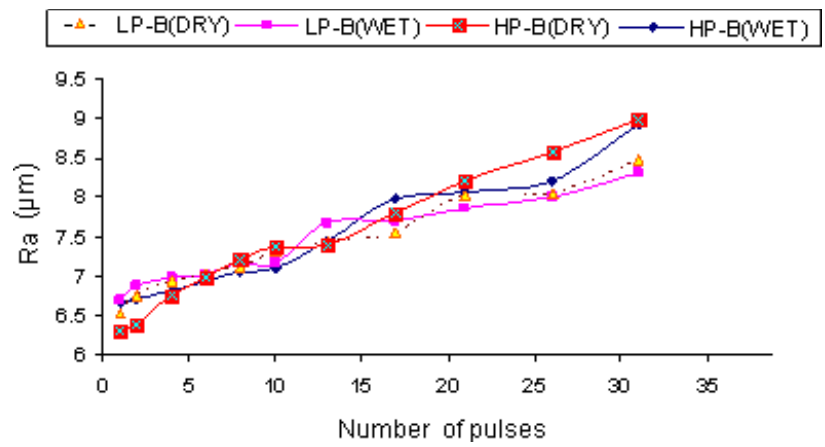

Figure 19: Porosity and moisture content on the surface roughness as a function of number of pulsed applied; $\mathrm{Ra}=7.70-8.49 \mu \mathrm{m} ; \mathrm{F}=3.06 \mathrm{~J} / \mathrm{cm}^{2}$. 


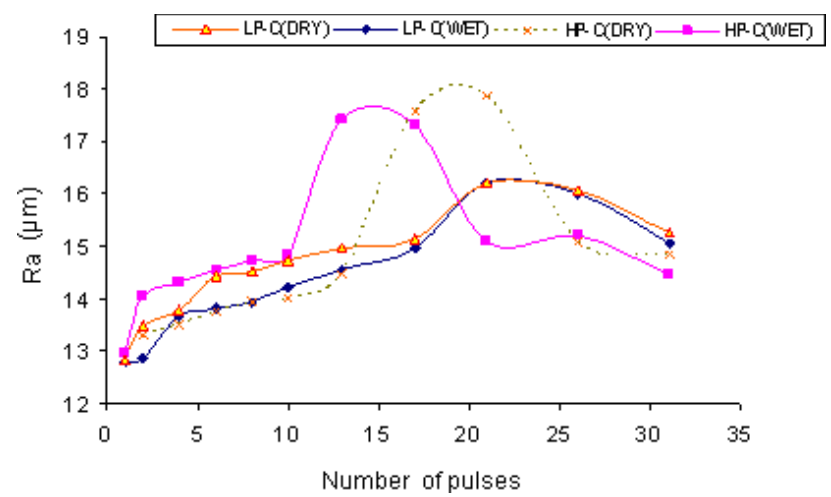

Figure 20: Porosity and moisture content on the surface roughness as a function of number of applied pulses; $\mathrm{Ra}=15.58-17.89 \mu \mathrm{m}$.

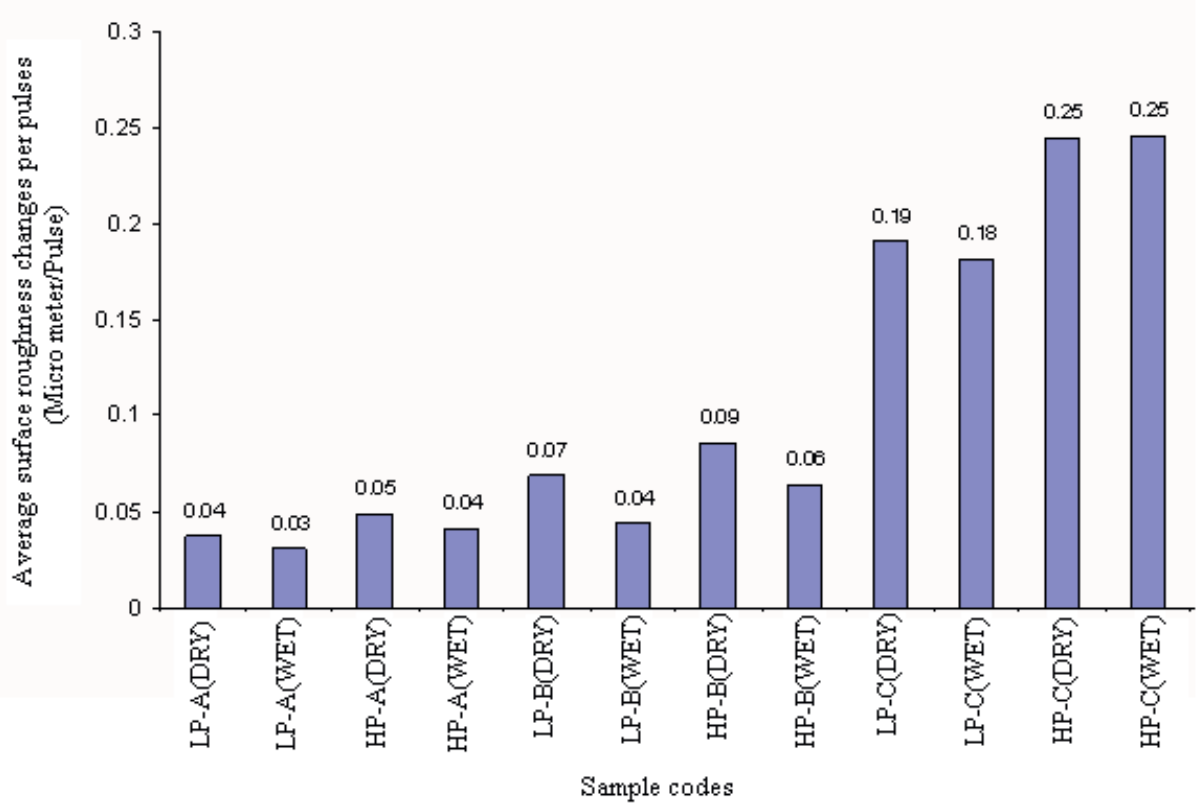

Figure 21: Effect of laser cleaning process on the surface roughness.

Nevertheless, both increase and decrease in surface roughness in more porous samples was higher than in less porous ones. This may lead to the conclusion that the removal of mortar caused by laser cleaning in highly porous samples is much more substantial and therefore may cause more severe damage to the substrate.

Quantitative analyses of the influence of porosity, moisture content and curing condition of mortars on the changes in surface roughness caused by laser cleaning are shown in Fig. 21.

The average surface roughness change per pulse may be used to quantify the effect of laser cleaning on the surface characteristics. The average surface roughness change per pulse was found to increase with the increase of initial surface roughness of mortar, 
leading to more damage in rougher surface. Furthermore, it was found to be higher for dry and/or more porous samples. For example, the average surface roughness change per pulse was 0.03 for LP-A(WET) and 0.05 for HP-A(DRY), indicating potential damage of dry and/or more porous samples. Since the flexural strength of the low porous sample was higher $\left(8.3 \mathrm{~N} / \mathrm{mm}^{2}\right)$ than that of the highly porous one $\left(7.4 \mathrm{~N} / \mathrm{mm}^{2}\right)$, the removal of mortar resulting from laser cleaning is demonstrable as more pronounced in highly porous samples.

\subsection{Surface roughness versus crack propagation}

Table 3 summarises the appearance of cracks on the mortar surfaces before and after the laser cleaning. In the case of rougher surfaces with low porosity, no cracks were observed. In addition, cracks were not observed on dry/low porous mortars with a moderate roughness. However, all low porous samples with smoother surfaces developed cracks (both wet and dry). This demonstrated that the energy dissipation through crack formation becomes less with the increase of initial surface roughness. Moreover, due to the presence of pit-holes, cracks always developed on highly porous surfaces.

The summary of effects of laser cleaning on surface roughness and crack formation in mortar surfaces are shown in Fig. 22. As initial surface roughness increased, alterations in roughness resulting from laser cleaning became more pronounced and the tendency of crack formation reduced.

Furthermore, in less porous samples, formation of cracks was more visible, while increased surface roughness was low. As a whole, the results indicated that whenever change in surface roughness was high, changes in crack density would be low. The relationship between the increase in surface roughness and crack density per pulse is shown in Fig. 23. As average surface roughness increment per pulse increased, the increment of average crack density per pulse was found to decrease.

Table 3: Appearance of cracks on surfaces before and after laser cleaning.

\begin{tabular}{lcc}
\hline & \multicolumn{2}{c}{ Cracks on the mortar surface } \\
\cline { 2 - 3 } Sample code & Before laser cleaning & After the laser cleaning \\
\hline LP-A(DRY) & No & Yes \\
LP-A(WET) & No & Yes \\
HP-A(DRY) & No & Yes \\
HP-A(WET) & No & Yes \\
LP-B(DRY) & No & No \\
LP-B(WET) & No & Yes \\
HP-B(DRY) & No & Yes \\
HP-B(WET) & No & Yes \\
LP-C(DRY) & No & No \\
LP-C(WET) & No & No \\
HP-C(DRY) & No & Yes \\
HP-C(WET) & No & Yes \\
\hline
\end{tabular}




\begin{tabular}{|c|c|c|c|c|c|c|c|}
\hline & \multicolumn{3}{|c|}{ Surface roughness } & \multicolumn{2}{|c|}{ Porosity } & \multicolumn{2}{|c|}{ Moisture content } \\
\hline & A & B & $\mathrm{C}$ & LP & $\mathrm{HP}$ & DRY & WET \\
\hline $\begin{array}{l}\text { Surface roughness } \\
\text { change }\end{array}$ & \begin{tabular}{c|c}
$\mathrm{Ra}$ & \\
$\mathrm{L}$ & \\
$\mathrm{Low}$
\end{tabular} & $\frac{\mathrm{N}}{\text { Moderate }}$ & $\begin{array}{c}\mathrm{N} \\
\text { High }\end{array}$ & Low & High & High & Low \\
\hline $\begin{array}{l}\text { Development of } \\
\text { crack }\end{array}$ & High & Moderate & Low & High & Low & $\begin{array}{l}\text { High(HP) } \\
\text { Low(LP) }\end{array}$ & $\begin{array}{l}\text { Low(HP) } \\
\text { High(LP) }\end{array}$ \\
\hline
\end{tabular}

Figure 22: Effect of surface roughness, porosity and moisture content of mortars on roughness increment and crack development resulting from laser cleaning.

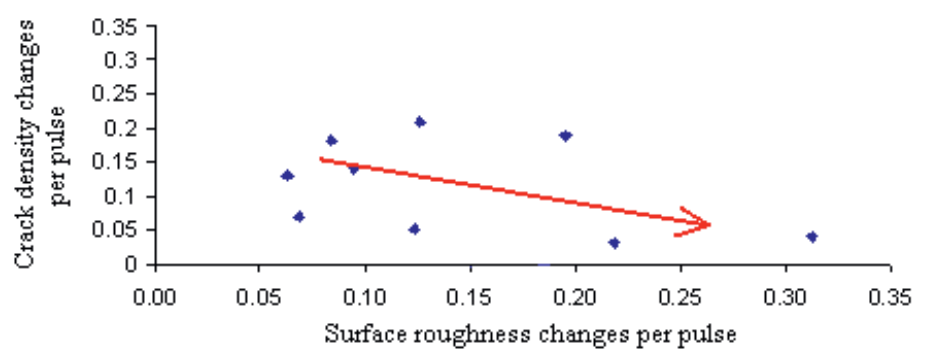

Figure 23: Relationship between crack formation and the increment of surface roughness (removal of mortar); $\mathrm{N}=31$.

This quantitative relationship shows that the decrease in change in surface roughness is accompanied by an increase in changes in crack density and therefore this relationship is based on energy balance.

\section{CONCLUSIONS}

Based on experimental investigations, the following conclusions can be formulated:

- Thermal stresses on the cementitious materials, resulting from the application of the laser may lead, in extreme cases, to severe crack formation, particularly around the pit-holes on highly porous surfaces. Cracks of wider openings may also form as a consequence of the expansion of water/air inside pores. The second mechanism is more prominent on smoother/denser mortars.

- The changes in surface roughness, with the number of pulses applied, depend mainly on the initial surface roughness of the mortar. The changes in surface roughness are mainly due to removal of mortar. In the case of smoother surfaces $(\mathrm{Ra}=2.28-2.49$ and $7.70-8.49 \mu \mathrm{m})$, surface roughness of the mortar increases with the number of laser pulses applied. The characteristic feature in rougher surfaces $(\mathrm{Ra}=15.58-17.89 \mu \mathrm{m})$ is an increase of roughness at the diminishing rate followed by a sudden decrease. The average change of surface roughness per pulse is high for rough, highly porous and/or dry surfaces.

- As initial surface roughness of mortars increases, the alterations in roughness resulting from laser cleaning become more pronounced and the tendency towards crack formation 
reduces. Whenever change in surface roughness is great, changes in crack density are low. Decrease in surface tensile strength results in the removal of mortar, which reduces crack formation.

- Laser-cleaned areas proved to be generally denser and more consolidated than the reference surface, due to vitrification of some parts of mortar following the laser cleaning process.

\section{REFERENCES}

[1] Cooper, M., Laser Cleaning in Conservation, an Introduction, Bath Press, UK, 1998.

[2] Costel, A., Garcia-Moreno, I., Gomez, C., Caballero, O. \& Sastre, R., Cleaning graffiti on urban building by use of second and third harmonic wavelength of a Nd:YAG laser: A comparative study. Applied Surface Science, 202, pp 86-99, 2003. doi: http://dx.doi. org/10.1016/S0169-4332(02)01241-2

[3] Matsui, I., Nagai, K., Yuasa, N. \& Ishigami, Y., Removing graffiti on concrete surface by laser, Nihon University, Taisei corporation Japan. Proc. of the Int. Conference, Dundee, Scotland: UK, 2002.

[4] Liu K. \& Garmire, E., Paint removal using lasers. Applied Optics, Optical Society of America, 34(21), 1995.

[5] Rozniakowski, K., P. Klemm, P. \& Klemm, A.J., Some experimental result of laser beam interaction with surface layer of brick. Building and Environment, 36, pp. 485-491, 2001. doi: http://dx.doi.org/10.1016/S0360-1323(00)00012-3

[6] Li, L., Steen, W.M., Modern P.J. \& Spencer, J.T., Laser removal of surface embedded contaminations on/in building structures. Proc. SPIE 2246, Laser Materials Processing and Machining, 84, 1994: doi:10.1117/12.193126. doi: http://dx.doi.org/ $10.1117 / 12.193126$

[7] Schmidt, M.J.J., Li, L. \& Spencer, J.T., An investigation into the feasibility and characteristics of using a $2.5 \mathrm{k} \mathrm{W}$ high power diode laser for paint stripping. Journal of Materials Processing Technology, 138, pp. 109-115, 2003. doi: http://dx.doi.org/ 10.1016/S0924-0136(03)00057-8

[8] Sanjeevan, P., Klemm, A.J. \& Klemm, P., Removal of graffiti from the mortar by using Q-switched Nd:YAG laser. Applied Surface Science, 253(20), pp. 8543-8553, 2007. doi: http://dx.doi.org/10.1016/j.apsusc.2007.04.030

[9] Sanjeevan, P., Klemm, A.J. \& Klemm, P., The effects of microstructural features of mortars on the laser cleaning process. Eighth International Symposium On Brittle Matrix Composites, Warsaw, Poland, 2006. doi: http://dx.doi.org/10.1533/9780857093080.45

[10] McStay, D., Wakefield, R., Murray M. \& Houston, H., Laser stone cleaning in Scotland, Historic Scotland, Edinburgh, 2005.

[11] Sanjeevan, P., The Effects of Geometrical Microstructure of Cementitious Composites on Laser Cleaning Process, PhD Thesis, Glasgow Caledonian University, UK, 2007.

[12] Hertz, K.D., Limits of spalling of fire-exposed concrete. Fire Safety Journal, 38(2), pp. 103-116, 2003. doi: http://dx.doi.org/10.1016/S0379-7112(02)00051-6

[13] Khan, M.I., Factors affecting the thermal properties of concrete and applicability of its prediction models. Building and Environment 37, pp 607-614, 2002. doi: http://dx.doi. org/10.1016/S0360-1323(01)00061-0 